\title{
Most Common Refusal Strategies Used by Students of English Teaching as a Foreign Language
}

\author{
ROSBERLY LóPEZ MONTERO \\ Sede del Pacífico \\ Universidad de Costa Rica
}

\begin{abstract}
This article explores the most common refusal strategies used by a group of English Teaching students from the Pacific Regional Center of the University of Costa Rica. Such analysis was carried out through a modified version of a Discourse Completion Test composed of six communicative situations: three requests and three offers. The investigation concluded that indirect strategies were preferred in all situations, and strategies of postponement (in which the speaker proposes the interlocutor to reschedule what has been offered or requested) and giving excuses or reasons, are the most frequently refusal strategies used in the situations under study.
\end{abstract}

Key words: linguistics, English, speech acts, culture

\section{Resumen}

El presente artículo explora las estrategias de rechazo de peticiones y ofrecimientos más usadas por un grupo de estudiantes de la Enseñanza del Inglés de la Sede del Pacífico de la Universidad de Costa Rica. Tal análisis se realizó mediante versión modificada de un Test de Discurso compuesto de seis situaciones comunicativas: tres peticiones y tres ofrecimientos. La investigación señala las estrategias indirectas como las predilectas en todas las situaciones; además, las estrategias en las cuales el interlocutor pospone lo ofrecido y ofrece excusas y motivos se encuentran como las usadas más frecuentemente.

Palabras claves: lingüística, inglés, actos de habla, cultura 


\section{Introduction}

his study explores the speech act of refusal in the context of English as a foreign language (EFL). Refusals represent one of the speech acts mostly used by speakers of any language; thus, they require a high degree of pragmatic competence and carry a great level of complexity; in fact, Gass and Houck, 1999, in Markus (2014), comment that the speaker who refuses a previous speech act, counts with little planning time to provide that refusal. In addition, refusals can threaten the interlocutor's face; therefore, different pragmatic strategies are necessary to avoid such situation. As Qusuay, Che and Raja (2011) state, "in many cultures, how one says "no" is probably more important than the answer itself" (p. 70), the way this negative answer is expressed may vary from culture to culture. As a matter of fact, "Depending on ethnicity and cultural-linguistic values, the speaker must know the appropriate form, its function, and when to use it" (Qusuay et al., 2011, p.71). This is why an analysis of the different strategies used to refuse offers and requests is relevant in the field of foreign languages, in this scenario, speakers not only manage the strategies used for refusing in their native language but must adapt those appropriate for their target language as well.

Pursuing this further, refusals belong to the speech act theory, which is framed within a linguistic-pragmatic approach. This theory was firstly developed by Austin (1991) from a perspective of the philosophy of language. He claims that every communicative act conveys a message that goes beyond what we actually say; in other words, whatever we say carries a message which has an effect on the listener, as it happens with refusals.

Needless to say, pragmatic competence is a relevant aspect to pursue when learning another language. Morkus (2014) quotes the words of Meier, 1995, "teaching pragmatic aspects of language can minimize intercultural communication breakdowns and reduce cultural stereotyping" (p. 1 ); hence, the importance of giving considerable attention to the field of pragmatics within an EFL context. Also, the status of the interlocutor is considered as one key aspect since this might determine the refusal strategy employed.

Given these points, this paper aims at responding the question: Which are the most common refusal strategies used by a group of English Teaching students considering the status between the speakers?

\section{Review of Literature}

\section{The speech act theory}

As it has been previously mentioned, the speech act theory is developed by Austin (1991) who comments that every speech act is simultaneously composed of three acts: locutionary, ilocutionary and perlocutionary. According to the author, the locutionary act refers to the speech act per se, whereas the ilocutionary act is a reflection of the speaker's intention, and the perlocutionary act, is the effect obtained through such speech act.

Furthermore, this theory is later developed by Searle (1986) who claims 
that everything we say is governed by rules. He details a categorization of speech acts according to their definition and usage in communication; for example, requests and orders belong to the category of directives, assertions and claims fall under the category of representatives, commissives include promises and threats, declaratives include acts like declaring a war or marrying a couple and expressives cover acts such as apologies, complaints and expressions of gratitude.

\section{The speech act of refusal}

Many authors disagree as to how to categorize refusals. On the one hand, Qusuay et al. (2011) affirm, as proposed by Searle, 1977, that refusals "belong to the category of the comissives because they commit the refuser to (not) performing an action" (p. 71). However, Asmali (2013) provides a different opinion, originally stated by Ellis, 2008 , that rejects such categorization indicating that refusals are more "an interactional turn rather than a speech act" (p. 114). Despite these two contrasting opinions, all sources consulted agree in that refusals constitute a response to a previous speech act. In this sense, Chen, Lei and Yanyin, 1995 (as cited in Morkus, 2014) state that when saying that this particular speech act is when "a speaker denies to engage in an action proposed by the interlocutor" (p. 87), like a request or an offer.

Moreover, previous studies have been made in the field of refusal strategies, considering different cultural backgrounds. To start with, Reinelt (1994) carries out a study of refusals in a Japanese language classroom. For this author, it is important for non-na- tive speakers to recognize possible refusals as well as to "develop techniques to overcome them" (Reinelt, 1994, p. 142).

Additionally, Nguyen (2006) deals with refusals of requests by a population of Australian native speakers of English and Vietnamese learners of English concluding that both populations differ in their way to refuse. By the same token, refusal strategies in English by Malay University Students are analyzed by Qusuay et al (2011).

Similarly, Asmali (2013) carries out a cross-cultural study comparing refusal strategies of Turkish, Polish and Latvian pre-service English teachers. Indeed, refusals have constituted a significant speech act to study in different cultures.

\section{The notion of face}

The term 'face' deals with politeness. In this sense, positive face refers to the image individuals have of themselves which aims to be recognized and reinforced by all society members. On the other hand, negative face deals with the desire people have for their actions to be approved. (Haverkate, 1994). The use given to politeness will determine whether both concepts of face would be threatened or not. A competent speaker will use different strategies so that such concepts of image are not threatened; in this sense, the use of indirect language is fatherly considered more polite.

Nguyen (2006), points out that

In everyday discourse, we often defer to interlocutors by avoiding subtle and personal topics, we reassure our partners, and we avoid open disagreement. 
If we realize that our messages are not clear to the listeners, we highlight important items and mark background information. When we do not understand other persons, we give nonverbal or non-threatening feedback to that effect. By doing so, we are taking the "face" of both ourselves and of the hearers into account. (p. 8)

Also, everyday communication deals with face-threatening acts. "These acts impede the freedom of actions (negative face), and the wish that one's wants be desired by others (positive face)-by either the speaker, the addressee or both" (Nguyen, 2006, p. 9). Indeed, refusals deal with the notion of face-threatening acts since they may threaten the interlocutor's positive face, "they may imply what he/she says is not favoured by the speaker" (Nguyen, 2006, p. 9). This is why speakers try to use strategies that protect their listeners' face.

\section{Methodology}

\section{Participants}

The population considered for this research study was a group of ten students from IV year of the English Teaching Major from the Pacific Regional Center of the University of Costa Rica. The reason why this group was selected is because they are currently at the highest level of the major for the Bachelor degree, which makes them possess a certain level of pragmatic awareness which has been developed through the years studying the language, and makes them suitable for this study. They are six women and four men, with ages between 22 and 24 years old.

\section{Instrument}

The instrument used consists of a modified version of a Discourse Completion Test by Asmali, 2013, and Beebe et al, 1990, as presented in Morkus (2014). Such instrument includes six communicative situations in written form considering aspects such as politeness and discourse situations occurred in unequal and equal status: three requests and three offers. There were requests and offers for each one of the following status: equal, low to high and high to low. All the situations were adapted to communicative contexts students could encounter in real life to make it as realistic as possible.

\section{Procedure}

Participants were provided with a copy of the Discourse Completion Test and were required to write down how they would refuse each of the situations in a real conversation in order to discover which strategies they would most commonly use to refuse: direct, indirect or adjuncts (Morkus, 2014). The situations were presented to them in English, considering situations in an equal status, low to high status and high to low. For a better appreciation of this, the table below shows a summary of every situation present in the instrument (Table 1).

\section{Analysis and Results}

The Discourse Completion Test was examined based on the classification of direct, indirect or adjuncts. As Qusuay et al. (2011) affirm, "this classification system has been widely 
Table 1

Situations in the Discourse Completion Test

\begin{tabular}{|c|c|c|}
\hline Situations & & Participants \\
\hline & & Classmate-classmate \\
\hline $1^{\text {st }}$ situation & $\begin{array}{c}\text { Request } \\
\text { Equal status }\end{array}$ & $\begin{array}{l}\text { A student has to refuse a classmates request of bor- } \\
\text { rowing the notes from the class he did not attend. }\end{array}$ \\
\hline $2^{\text {nd }}$ situation & $\begin{array}{c}\text { Request } \\
\text { Low to high status }\end{array}$ & $\begin{array}{l}\qquad \text { Employee-Boss } \\
\text { An employee has to refuse his boss's request of } \\
\text { working some extra hours. }\end{array}$ \\
\hline $3^{\text {rd }}$ situation & $\begin{array}{c}\text { Request } \\
\text { High to low status }\end{array}$ & $\begin{array}{l}\text { College student- little brother's friend } \\
\text { A speaker has to refuse a request from his } \\
\text { young brother's friend to help him with a } \\
\text { school project. }\end{array}$ \\
\hline $4^{\text {th }}$ situation & $\begin{array}{c}\text { Offer } \\
\text { Low to high status }\end{array}$ & $\begin{array}{l}\text { Employee-employer } \\
\text { An employee from a tourism company has to } \\
\text { refuse his boss's offer to relocate to a better } \\
\text { paid position, but in a much farther place. }\end{array}$ \\
\hline $5^{\text {th }}$ situation & $\begin{array}{c}\text { Offer } \\
\text { Equal status }\end{array}$ & $\begin{array}{l}\text { Friend-friend } \\
\text { A speaker has to refuse a friend's offer to have } \\
\text { dessert after a very big meal. }\end{array}$ \\
\hline $6^{\text {th }}$ situation & $\begin{array}{c}\text { Offer } \\
\text { High to low status }\end{array}$ & $\begin{array}{l}\text { Teaching assistant-janitor } \\
\text { A teaching assistant has to refuse the offer } \\
\text { from the university's janitor to pay for a china } \\
\text { figurine he accidentally breaks. }\end{array}$ \\
\hline
\end{tabular}

used and adapted to examine refusals among native and non-native speakers in different languages" (p. 74); therefore, it proves to be pertinent in this analysis as well.

In order to clarify this classification of strategies, it is important to express that direct refers to refusals that are delivered in a direct manner, like 'no', or 'I refuse', with no mitigating formulas whatsoever. In contrast, indirect are phrases that possess all sort of mitigating formulas; hence, they are told indirectly, such as excuses, apologies or explanations. Following this, adjuncts constitute "expressions used to convey support to the interlocutor and help him or her save face" (Morkus, 2014, p. 91). To exemplify this clas- sification, table 2 shows examples for every one of the categories, based on Morkus (2014), modified from Beebe et al., 1990. This categorization was used for this investigation.

Having this clear, an analysis of every one of the situations will be done in the following lines in order to determine the most common strategies used to refuse in each case.

\section{Request: equal status}

In this type of request, when both the speaker and the interlocutor have the same status and one has to refuse an offer, different strategies were used. Interestingly, however, this was the only opportunity from 
Table 2

Categories of refusal strategies

\begin{tabular}{lll}
\hline \multicolumn{1}{c}{ Strategies } & \multicolumn{1}{c}{ Categories } & \multicolumn{1}{c}{ Formulas } \\
\hline Direct & & "No" / "I refuse" \\
Indirect & Excuse / reason & "I am really busy" \\
& Statement of regret & "I am sorry" \\
& Postponement & "Maybe in another time" \\
& Wish & "I wish I could" \\
& Setting Conditions of acceptance & "Maybe if you had let me know before- \\
& & hand" \\
Adjuncts & Expressions of gratitude & "Thank you very much" \\
& Statements of positive opinion & "It's delicious" \\
& Statement of empathy/concern & "I'm sorry you're having problems" \\
\hline
\end{tabular}

Source: Morkus (2014)

all the communicative situations in which the participants used lack of empathy as one of the strategies. This can be easily understood if one sees that the person requesting is a classmate who is usually late to class and misses lessons frequently; thus, the lack of empathy could be a way to try to avoid this type of request in the future. Nonetheless, these never come alone; the phrases showing some lack of empathy are accompanied by other formulas like regret or reason, as can be seen in the following examples:

Since you don't come to classes, I see you are not interested in the topic being studied; you are not responsible.

In the example above, the student concludes that since his/her classmate is not interested in going to class, there is no reason to be concerned about his/ her situation; in other words, that is a problem for the person who needs the notes, not for the person who is being asked for help.
Another example:

I consider that you don't do your best, so I think this time you have to face your responsibilities by yourself (Lack of empathy) as I'm doing. I'm sorry, but this time I can't help you. (Regret)

In this case, lack of empathy refers to the fact of not being interested in the results the peer may have for not getting the class notes.

\section{Request: low to high}

In this scenario, the participants have to refuse a request from their boss. In this case, different indirect strategies were identified: gratitude, reason, conditions of acceptance, regret, wish and postponement.

I'm sorry, Mr..., today I can't help you (Regret) because I already have plans and I can't cancel them. (Reason) But if you need me another time, I can help you. (Postponement) 
Excuse me, sir, but I have an appointment and it is very difficult for me to stay until 9:00. (Reason)

I have a meeting with my mother that came to visit me, actually, she is waiting at home and (Reason) I do not want to let her down because of work. If my mom would not be there, I will help you to finish. (Setting conditions of acceptance)

I would really like to do it. (Wish) The problem is that for that day I promised to attend an important meeting and I have to be responsible (Reason). You know that if I would have not done the commitment, I would help you. I hope you can understand (Setting conditions of acceptance). If you decide to do it another day, let me know. (Postponement)

\section{Request: high to low}

In the request of high to low (where the person in the higher status has to refuse an offer from someone in a lower status), all responses used the indirect strategy of postponement, along with reasons and phrases of regret and wish, as can be appreciated in the following samples:

I can't do it right now because I'm in a hurry (Reason), maybe tomorrow I can help you. (Postponement)

Oh! Friend, I would like to help (Wish), but your brother is almost ready and we need to go, maybe in another time, ok? (Postponement)

I' m sorry, but your brother and I are late for the concert but if you want (Regret), we can do it another day, whenever you want. (Postponement)
This demonstrates that when refusing a low status person, the speaker tries to look for this person's satisfaction, and avoid disappointment by proposing to reschedule the event of the request.

\section{Offer: low to high}

In this situation, the participants are asked to refuse an offer for another job. In this case, the boss is really pleased with the job done in the company; so, he decides to offer relocation with a higher payment but in a place far from home. For this particular scenario, the expressions of gratitude were predominant: six out of ten showed a phrase for appreciation, the other four included a reason for the rejection of the offer.

Some examples are shown as follows:

I'm very glad you have taken me into consideration (Appreciation) for this work, and I don't want to sound rude, but now I can't take it. Thank you for the offer. (Gratitude)

I'm glad you are offering that to me. It's an honor and I'm thankful (Gratitude) for that but I cannot accept it because right now it is not possible for me. (Reason)

\section{Offer: equal status}

Similarly, expressions of gratitude were used at the time to refuse an offer from a peer; in this case, from a friend who is offering more dessert after a big meal. Along with gratitude, two more strategies were mostly identified: postponement and positive opinion, in this case, besides showing 
appreciation for the offer, it was important to express that the food was delicious; otherwise, it could be considered rude. In this case, even though the offer is being rejected at the moment, it would be accepted later, so it will not be a complete rejection.

Some examples:

Thank you, everything was delicious (Gratitude) but I cannot eat more, I do not want to get sick. (Positive opinion) Tomorrow we could eat more. (Postponement)

I feel honored that you want me eat this (Gratitude), but I'm so full, tomorrow, I promise, I will eat it, it (Postponement) looks delicious (Positive opinion), but I might throw up even if I drink water. Please, keep it for me and I'll eat later (Postponement)

It is important to mention that not all responses included the three different strategies mentioned above (gratitude, postponement and positive opinion). Some only used two whereas others used different ones:

Sorry (Regret), but I feel so full (Reason) maybe another time. (Postponement)

Thank you very much (Gratitude) but I have eaten a lot. (Reason)

\section{Offer: high to low}

In this scenario, in which an offer from a low status has to be refused, the participants showed a high degree of empathy towards the interlocutor, the majority of them used the expression "don't worry" at some point, along with jokes in some cases.

\section{For instance:}

It's not a big deal! Don't worry. I actually was going to throw it away because I never liked it. But you did the work for me. (laugh)

Don't worry! It is not necessary! It was not your fault, you did not mean it! We are ok! Don't beat yourself up!

It wasn't your fault, do not worry. It wasn't important to me, take it easy. Just clean it and the problem is solved!

In this case, what was important was to show the other person that there was no need to even make the offer and try to create a friendly atmosphere that would additionally protect the interlocutor's face.

Now, the following graphs will provide a general view of the most common strategies employed, including the requests as well as the offers.

\section{Graph 1}

Refusal strategies for low to high

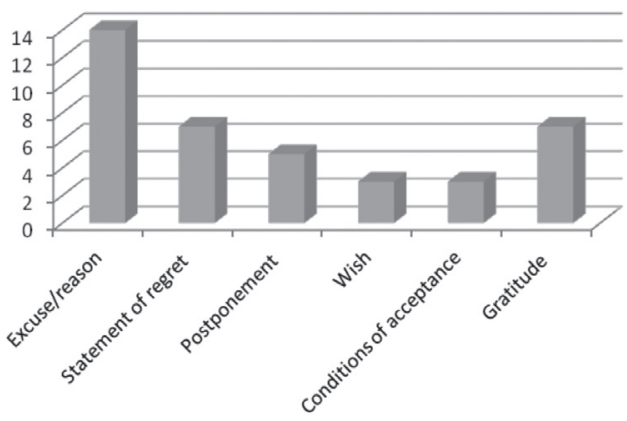

As it is shown in Graph 1, the most common refusal strategy for someone of a higher status is giving reasons or excuses. It seems that it is important for the speaker to maintain a positive 
Graph 2 Refusal strategies for equal status

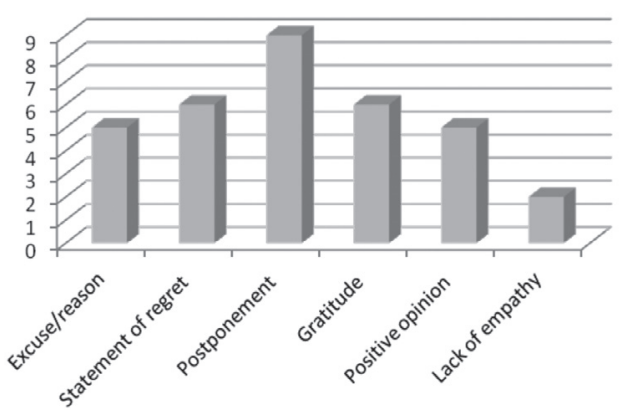

image towards the person requesting or offering, which in both cases are constituted by a boss.

This reflects that the population of the study is pretty aware of the hierarchal relationship played in the society and how important it is to maintain a good image before those in a higher status. A way to do so, is to offer a justification instead of a direct no, a student initiating in the study of another language may not understand this and use a more direct strategy to refuse what is being asked. As well, he may lack linguistic resources to use less direct strategies.

In Graph 2, it is necessary to highlight that the expressions of gratitude as well as the statements of positive opinion in this case belong to the offer, and not the request. The lack of empathy, on the other hand, does belong to the refusal for the request. This is an important point to mention since it is not the same to refuse a request from a distracted classmate than an offer from a generous friend.

However, for both cases, postponement constitutes the strategy mostly used when refusing something to someone in the same status. This demonstrates that for the speakers, a way to be polite is to reschedule the event

\section{Graph 3 \\ Refusal strategies for high to low}

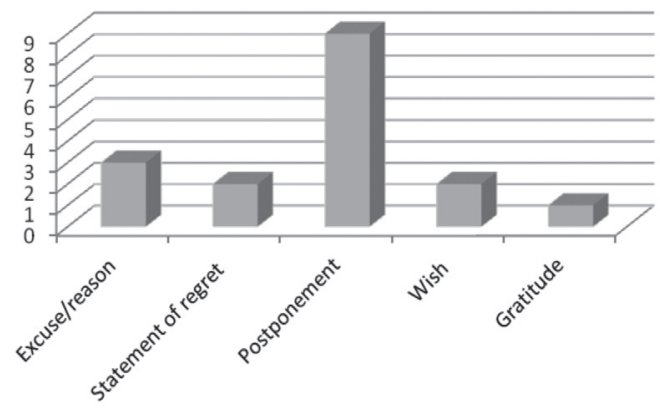

so the interlocutor notices there is willingness to fulfil the demand.

As it is shown in Graph 3, the indirect strategy of postponement was mostly used for refusing both offers and requests to an interlocutor of a lower status. This could be due to the fact that participants find the need to satisfy the students request or offer, to obtain their approval even though what they asked for has been refused.

In sum, all the above provides valuable insights in the field of pragmatics for students who are learning English as a foreign language. Such learning process goes beyond the memorization of grammatical and pronunciation rules, it involves actual interaction among speakers which, at the same time, varies from culture to culture. That is to say, that the use of the different refusal strategies depending on the social context demonstrates the degree of awareness of the speakers in a language other than their native tongue. Additionally, the fact of belonging to a senior level, gives the participants of this study more linguistic resources to use at the time to refuse orders and requests; also, it permits them to determine what to say depending on who the interlocutor is. This is 
of high relevance in the field of learning English because it provides both teachers and students different possible strategies to refuse appropriately.

\section{Conclusions}

The investigation concludes that indirect strategies were preferred in all situations, and strategies of postponement, in which the speaker proposes the interlocutor to reschedule what has been offered or requested, and giving excuses or reasons, are the most frequently refusal strategies used in the situations under study.

In spite of the fact that some communicative situations were between peers, every participant avoided the use of direct strategies in all the situations, since these represent an impolite way to refuse. This is in concordance with what is claimed by Qusuay et al (2011) when affirming that "saying 'no' to someone's face is interpreted as an insult to the other person" (p. 75); therefore, there was always a formula to mitigate directness, like adding an excuse or a reason, as a way to justify the refuse without insulting the interlocutor.

Interestingly, the participants of this study seem to find using only one indirect strategy insufficient. Most of the times, they used two or three in one refusal, this might stand for a general feature of Costa Rican culture.

Even though the population considered for this study does not constitute a large number, it is possible to make some general conclusions on the topic that will provide a primary foundation for future studies. In addition, for future research in the field, it is recommended to use role-plays in order to search for more natural responses. Nonetheless, and despite of the fact that written responses can have the limitation of spontaneity, they constitute a simpler instrument to analyze which equally provides valuable insights for the field.

\section{Bibliography}

Asmali, M. (2013). Cross-cultural comparison of non-native speakers' refusal strategies in English. International Journal of English Language \& Translation Studies. 1 (3), 111-135.

Austin, J. (1962/1991). Cómo hacer cosas con palabras. Barcelona: Editorial Paidós.

Haverkate, H. (1994). La cortesía verbal. Estudio pragmalingüístico. Madrid: Editorial Gredos, S.A.

Morkus, N. (2014). Refusals in Egyptian Arabic and American English. Journal of Pragmatics. 70, 86-107.

Nguyen, T. (2006). Cross-cultural pragmatics: refusals of requests by Australian native speakers of English and Vietnamese learners of English. (Dissertation for the Degree of Master of Arts in TESOL studies). University of Queensland.

Qusuay, H., Che, S. \& Raja, R. (2011). Refusal strategies in English by Malay University Students. Journal of Language Studies. 11 (3), 69-81.

Reinelt, R. (1994). Refusals in Japanese foreign language classrooms. Intercultural Communication Studies. 4 (1), 121-147.

Searle, J. (1969/1986). Actos de habla. Ensayo de filosofía del lenguaje. (2a. ed.). Madrid: Ediciones Cátedra, S.A. 


\section{APPENDIX}

Dear Respondent,

This instrument has been designed to investigate 'Refusal Strategies by English Teaching Students". You are kindly requested to give the most appropriate responses to the situations given below. The answers should be written in the provided spaces and in English. It will take you approximately 15 minutes to complete the questionnaire. On the questionnaire, you will fill in several communicative situations in which an individual is requesting to do something for or with him/her as well as offering to do something for you. Imagine that you do NOT want to comply with their request or offer. Please respond as you would in a real conversation. The information obtained in the course of this study will be kept confidential and used only for the purposes of academic research.

Age:

Male ( ) Female ( )

\section{Request: equal status}

You are one of the best students in class. You are known among your classmates for taking very good notes during the lectures. Yesterday the professor just announced that there would be an exam next week. One of your classmates, who you don't interact with outside of class, and who misses class frequently and comes late to class, wants to borrow your lecture notes for the exam. You have previously helped this student several times, but this time you just feel that you cannot give him the lecture notes again. You refuse the request by saying:

\section{Request: low to high}

You have been working part-time at a copy place for the past 7 months, and you have a good relationship with your 45- year-old boss who is pleased with your work. The copy place opens at 7:00 a.m. and closes at 9:00 p.m. and your work shift is Monday through Friday from 2:00 p.m. to 6:00 p.m. This week is a very busy one since it is the first week of the semester and many students come to copy their materials. On Friday night your boss asks you to stay for three more hours, until 9:00 p.m., to help him get all the copies that need to be taken by next Monday. But you cannot work these extra hours. You refuse the request by saying:

\section{Request: high to low}

You stop by your friend's house to pick him up to go to a concert where you will meet other friends. Your friend has one younger brother in high school. Your friend is running a little bit late and still needs about $10 \mathrm{~min}$ to get ready. In the meantime his parents are entertaining you while you are waiting for him in the living room. While you are chatting with his parents, his younger brother, whom you met a couple of times before, comes by to say hi, and to ask for your help with something. He is working on a school project and needs to interview you for this project. You cannot, however, help him at this time. You refuse the request by saying:

\section{Offer: low to high}

You have been working for a tourism agency for almost 3 years now and 
you have a good relationship with your boss. Your boss has been very pleased with your work and creativity and has decided to offer you a promotion and a pay raise. However, this promotion involves relocating to Osa Península, from your hometown in Puntarenas. Although you like the offer, you cannot accept it. You refuse the offer by saying:

\section{Offer: equal status}

You are visiting a friend of yours who you have not seen for almost a year. Your friend is originally from the United States and is so delighted that you are visiting. He prepared a big meal for you with traditional food as well as some nice typical dessert. At the end of the meal you feel so full, but your friend offers you more dessert and insists that you should eat it. But you actually cannot. You refuse the offer by saying:

\section{Offer: high to low}

You are a teaching assistant at a major university in the US. You usually like to stay late in your office on campus. Sometimes you stay as late as 7:00 or 8:00 p.m. and that's usually the time when janitors come to clean offices. They are usually hesitant to clean your office when they see that you are still working. However, you usually just tell them to go ahead and clean the office any way. One night while you're still working in your office one of the janitors comes in and starts cleaning. You have already seen this janitor several times before and exchanged greetings with him. While he is cleaning your office he accidently knocks down a small china figurine and breaks it into pieces. The janitor apologizes and insists that he should pay for it. However, for you it's not a big deal, and you refuse to accept money from him. You refuse the offer by saying:

Thank you for your participation! 